\title{
Biodegradation of Polycyclic Aromatic Hydrocarbons in Mangrove Sediments Under Different Strategies: Natural Attenuation, Biostimulation, and Bioaugmentation with Rhodococcus erythropolis T902.1
}

\author{
Firmin Semboung Lang • Jacqueline Destain • Frank Delvigne • \\ Philippe Druart • Marc Ongena • Philippe Thonart \\ Received: 27 January 2016 / Accepted: 28 July 2016 / Published online: 4 August 2016 \\ (C) Springer International Publishing Switzerland 2016
}

\begin{abstract}
Polycyclic aromatic hydrocarbons (PAHs) are pollutants that occur in mangrove sediments. Their removal by bacteria often depends on specific characteristics as the number of benzene rings they possess and their solubility. Their removal also depends on environmental factors, such as $\mathrm{pH}$, temperature, oxygen, and the ability of the endogenous or exogenous microflora to metabolize hydrocarbons. With the aim of treating mangrove sediments polluted by hydrocarbons in a biological way, a biodegradation experiment was conducted using mangrove sediments artificially contaminated with a mixture of four PAHs. The study used Rhodococcus erythropolis as an exogenous bacterial strain in order to assess the biodegradation of the PAH mixture by natural attenuation, biostimulation, bioaugmentation, and a combination of biostimulation and bioaugmentation. The results showed that the last three treatments were more efficient than natural attenuation. The biostimulation/bioaugmentation combination proved to be the most effective $\mathrm{PAH}$ degradation treatment.
\end{abstract}

F. S. Lang $(\bowtie) \cdot J$. Destain $\cdot$ F. Delvigne $\cdot$ M. Ongena $\cdot$

P. Thonart

Centre Wallon de Biologie Industrielle, Université de Liège -

Gembloux Agro Bio-Tech, Passage des Déportés 2,

B-5030 Gembloux, Belgium

e-mail: langsemb@yahoo.fr

P. Druart

Centre Wallon de Recherche Agronomique (CRA-W), Chaussée de Namur 24, B-5030 Gembloux, Belgium
Keywords Mangrove $\cdot$ Biodegradation $\cdot$ Hydrocarbons

\section{Introduction}

Polycyclic aromatic hydrocarbons (PAHs) constitute an important class of organic compounds with two or more fused aromatic rings that persist in soils and sediments (Cerniglia 1993; Marini et al. 2013). This class of toxic environmental pollutants has accumulated into the environment mainly because of anthropogenic activities. PAHs are generated by natural combustion processes as well as human activities. Anthropogenic inputs from atmospheric deposition, industrial stack emission, oil spills, ship traffic, urban runoff, and the illegal discharge of industrial effluents have led to a significant accumulation of PAHs in the marine biotope (Luan et al. 2006). Mangrove ecosystems, which are important inter-tidal estuarine wetlands along coastlines in tropical and subtropical regions, are exposed to human activities and are subject to PAH contamination from tidal water, river water, and land-based sources (Yu et al. 2005). Ho Chung swamp covers a mangrove area of 2.37 ha and has been polluted by vehicle exhausting deposition, and discharge of industrial, livestock, and household waste and wastewater. The PPAHs concentrations (sum of 16 USEPA priority PAHs) of surface sediments varied from 1162 to $3322 \mathrm{mg} \mathrm{kg}^{-1}$ freeze-dry weight with mean and standard deviation values (based on three replicates) of $2202 \pm 959 \mathrm{mg} \mathrm{kg}^{-1}$ freeze-dry weight. The silt and clay percentage, organic matter content, and $\mathrm{pH}$ in this mangrove sediment were $36 \pm 12,4.59 \pm 0.58$ dry weight, 
and $7.24 \pm 0.24 \%$, respectively (Yu et al. 2005). PAHs present in soil can have a toxic effect on many plants, microorganisms and invertebrates (Tian et al. 2008).

According to Juhasz (2000), since 1970, the research on the biological degradation of PAHs has demonstrated that bacteria, fungi, and algae have catabolic abilities that could be used for the remediation of PAHcontaminated soil and water. Mangrove sediments contain a diverse group of indigenous bacterial species capable of degrading PAH efficiently (Tam et al. 2002; $\mathrm{Ke}$ et al. 2003). Bioremediation has been shown to be effective in remediating soils contaminated with low molecular weight PAHs (Mueller et al. 1991; Kastner and Mahro 1996; Banerjee et al. 1995), but high molecular weight PAHs are generally recalcitrant to microbial attack (Park et al. 1990; Erickson et al. 1993; Cerniglia 1992).

Microbial degradation is believed to be one of the major processes involved in cleaning up PAHcontaminated sediments (Hughes et al., 1997). Ramsay et al. (2000) reported that a large number and a wide diversity of PAH-degrading microorganisms were found in mangrove sediments. Ke et al. (2003) showed that over $90 \%$ of pyrene was removed from contaminated mangrove microcosms in 6 months. In order to enhance biodegradation efficiency, three remedial strategies were proposed by Iwamoto and Nasu (2001): natural attenuation, bioaugmentation, and biostimulation.

Natural attenuation uses indigenous microorganisms to degrade contaminants and has the advantage of being natural, involving no external modification of the environment (Mills et al. 2003). Therefore, it also avoids causing any damage in ecologically sensitive mangrove habitats (Dowty et al. 2001). However, intrinsic bioremediation often takes a long time to complete because of the limited population size of the indigenous degrading microorganisms (Forsyth et al. 1995). Biostimulation, based on supplying additional nutrients or substrates to stimulate the degradation of native microorganisms, can also be used to activate biodegradation (Riser-Roberts 1998), especially in environments such as mangrove sediments where nutrients are often found in low concentrations (Burns et al. 1999). The microbial activity to degrade oil contamination can be stimulated by addition of soluble inorganic fertilizer to mangrove sediments. However, the effectiveness of these strategies depends on the sediments and the contaminants considered (Balba et al. 1998). Bioaugmentation, based on inoculating microorganisms with the required degradation capability, might be a way of enhancing the biodegradability of toxic contaminants. Bioaugmentation with competent degrading strains of bacteria can stimulate the rate and the extent of biodegradation in appropriate environments (Vogel 1996).

The current study therefore aims to (1) assess the potential degradation ability of Rhodococcus erythropolis T902.1, an exogenous bacterial strain, in the presence of a mixture of four PAHs, (2) assess the ability of R. erythropolis in pure culture and in association with the endogenous microflora, and (3) evaluate and compare different PAH degradation strategies.

\section{Materials and Methods}

\subsection{Mangrove Sediments and PAH Analysis of Sediments}

Mangrove sediments were collected from the mangrove ecosystem of the Wouri estuary in Cameroon. This ecosystem receives effluent from industrial activities upstream. The hydrocarbon index for PAH Borneff is less than $0.18 \mathrm{mg} / \mathrm{kg}$ dry matter.

\subsection{Microorganisms}

We used the indigenous microflora of the mangrove sediments for treatment by natural attenuation and biostimulation. Rhodococcus erythropolis T902.1 was added to the indigenous microflora for treatment by bioaugmentation. The Rhodococcus genus is a very diverse group of bacteria with the ability to degrade a large number of organic compounds, including some of the most problematic compounds in terms of recalcitrance and toxicity. Rhodococcus bacteria appear to have adopted a strategy of hyper-recombination associated with a large genome (Larkin et al. 2005). Rhodococcus sp. appears to be a good candidate for use in bioaugmentation, since this genus is ubiquitous (Bell et al. 1998) and can degrade a broad range of aliphatic, branched, cyclic, (polycyclic) aromatic, sulfur-containing, and chlorinated hydrocarbons (Martinkova et al. 2009; Larkin et al. 2010a, 2010b). Rhodococcus sp. can also withstand environmental stresses, such as low temperature, a low water content, high $\mathrm{pH}$ values, a high salinity, lacks of nutrients, and the presence of toxic solvents or pollutants (Whyte et al. 1999; de Carvalho 2010, 2012; de Carvalho et al. 2014). 
Rhodococci synthesize mycolic acids and trehalolipids to modify their membrane hydrophobicity in order to protect themselves from these adverse environments and to solubilize and assimilate hydrophobic substrates that are poorly bioavailable in soil (Lang and Philp 1998; Kuyukina et al. 2005; Kuyukina and Ivshina 2010). Rhodococcus erythropolis T902.1, despite a limitation in oxygen transfer, enhanced a greater hydrocarbons degradation compared to the biostimulation treatment. $R$. erythropolis T902.1 is the desiccation-tolerant strain. This strain is suitable for large production in bioreactors and conservation in a powdered form before its use in real conditions (Weekers et al. 1999; Masy et al. (2016).

\subsection{Polycyclic Aromatics Hydrocarbons}

Polycyclic aromatic hydrocarbons are nonpolar, hydrophobic compounds that do not ionize. As a result, they are only slightly soluble in water. In this study, we used four PAHs: anthracene (Ant), phenanthrene (Phe), pyrene (Pyr), and fluoranthene (Flt), purchased from UCB in Belgium (purity $>97 \%$ ). Anthracene contains three benzene rings, its molecular weight is 178.24 , and the octanol-water partition coefficient (logKow) is 4.54 . Phenanthrene has three benzene rings as well, its molecular weight is 178.24 and the logKow is 4.57. Pyrene has four benzene rings, its molecular weight is 202.26 and its $\log$ Kow is 5.18. Finally, fluoranthene also contains four benzene rings, its molecular weight is 178.24 and its $\log$ Kow is 4.18 .

\subsection{Biodegradation Studies}

Mangrove sediments, up to a depth of $10 \mathrm{~cm}$, were collected from the mangrove area of the Wouri estuary, which covers the Mungo Wouri and Dibamba mangroves in Cameroon at low tide. The sediments were artificially contaminated using the method described by Puri et al. (1997), Ke et al. (2003), and Tam et al., (2008), with some slight modifications. In each flask, $10,000 \mathrm{mg} \mathrm{kg}^{-1}$ of dry matter of each PAH used (anthracene, phenanthrene, pyrene, and fluoranthene) were dissolved in $25 \mathrm{ml}$ of acetone and mixed with $100 \mathrm{~g}$ of mangrove sediment. The flasks were left open for 2 days in order to allow the acetone to evaporate and the sediment to adsorb the PAHs. The PAH concentration in each flask was about $10,000 \mathrm{mg} \mathrm{kg}^{-1}$ of dry matter. A volume of $100 \mathrm{~mL}$ of artificial seawater with a salinity of $10 \%$ (parts per thousands) was added into each flask.

Two series of three flasks, each containing $100 \mathrm{~g}$ of artificially contaminated mangrove sediment, were sterilized by autoclaving at $121^{\circ} \mathrm{C}$ for $30 \mathrm{~min}$. We added in one series $100 \mathrm{~mL}$ of medium containing $70 \%$ of seawater, $30 \%$ of mineral salt medium (MSM) and $R$. erythropolis T902.1. In other series, we added $100 \mathrm{~mL}$ of medium containing $100 \%$ of seawater and $R$. erythropolis T902.1. Another series of three flasks, also sterilized by autoclaving, only contained PAHs and $100 \mathrm{~mL}$ of seawater. This series was used as the control to determine any abiotic loss of PAHs. For the natural attenuation treatment, we used three flasks containing sterile noncontaminated sediment and artificial seawater. For the biostimulation treatment, another set of three flasks were treated as above, with $30 \%$ of MSM added. For the bioaugmentation treatment, we used flasks with nonsterile contaminated sediment, artificial seawater, and $R$. erythropolis as the pure bacterial strain. For the treatments combining biostimulation and bioaugmentation, we added $R$. erythropolis and $30 \%$ MSM to three flasks containing nonsterile contaminated sediment. For the bioaugmentation sediment slurry, the $R$. erythropolis starter was inoculated in order to give an initial inoculum concentration of $10^{-7} \mathrm{cell} \mathrm{m}^{-1}$ at the beginning of each degradation experiment (after the adsorption of the spiked PAHs into the sediment). The MSM was composed of (in mg L ${ }^{-1}$ ): $\left(\mathrm{NH}_{4}\right)_{2} \mathrm{SO}_{4}, 1,000 ; \mathrm{K}_{2} \mathrm{HPO}_{4}, 800$; $\mathrm{KH}_{2} \mathrm{PO}_{4}, 200 ; \mathrm{MgSO}_{4} \cdot 7 \mathrm{H}_{2} \mathrm{O}, 200$; and $\mathrm{CaCl}_{2} \cdot 2 \mathrm{H}_{2} \mathrm{O}$, 100. The trace elements were composed of: $\mathrm{FeSO}_{4} \cdot 7 \mathrm{H}_{2} \mathrm{O}, 12 ; \mathrm{MnSO}_{4} \cdot 7 \mathrm{H}_{2} \mathrm{O}, 3 ; \mathrm{ZnSO}_{4} \cdot 7 \mathrm{H}_{2} \mathrm{O}, 3$; $\mathrm{CoSO}_{4} \cdot 7 \mathrm{H}_{2} \mathrm{O}$, 1 ; and $\left(\mathrm{NH}_{4}\right)_{6} \mathrm{Mo}_{7} \mathrm{O}_{24} \cdot 4 \mathrm{H}_{2} \mathrm{O}, 1$. The salinity of the MSM was adjusted to $10 \%$, similar to the artificial seawater. The PAHs were extracted from the sediments every 7 days and over a period of 5 weeks. The extraction procedure was based on an analysis of PAHs by high-performance liquid chromatography (HPLC) Agilent 1100 series, as proposed by Wannoussa et al. (2015), with slight modifications. Thus, $1 \mathrm{~g}$ of humid sediment sample was put into 18 $\mathrm{ml}$ glass tubes, and an equivalent weight of anhydrous sulfate and $10 \mathrm{~mL}$ of hexane were added. The mixture was homogenized by vortexing and placed in an ultrasonic bath for $1 \mathrm{~h}$. The tubes were then placed into a horizontal shaker protected from light for $16 \mathrm{~h}$, and the organic phase was transferred to $15-\mathrm{mL}$ Falcon tubes. After centrifugation and transfer into a new tube, the residue was extracted a second time with $10 \mathrm{~mL}$ of 
hexane and put into a glass balloon. The hexane was evaporated using a rotavapor (BUCHI ROTAVAPOR R-200) heated to $55^{\circ} \mathrm{C}$, and the dry extract was taken up in $10 \mathrm{~mL}$ of methanol. Then, $1 \mathrm{~mL}$ of this solution was put into an HPLC vial and closed with a septum cap and a crimper. The samples were next sent to HPLC analysis. The HPLC analyses were performed using Agilent 1100 Series equipment and a C18 column (LiChroCART ${ }^{\circledR}$ 250-4.6 HPLC-cartridge Purospher ${ }^{\circledR}$ STAR RP-18 endcapped $5 \mu \mathrm{m}$, Merck, D) maintained at $30^{\circ} \mathrm{C}$.

\subsection{Enumeration of Total Aerobic Heterotrophs and PAH-Degrading Bacteria}

The enumeration of the total microflora and active microflora was done by using the successive dilution method, with the dilution spread on Petri dishes. In this way, $1 \mathrm{~g}$ of mangrove sediment sample was recovered from each flask every 7 days. The sample was placed in a test tube containing $9 \mathrm{ml}$ of peptone water. For the active microflora, the spreading was done on a solid MSM containing $10 \mathrm{mg} / \mathrm{kg}$ of dry matter of diesel as the sole carbon source. Each dilution was spread three times. After 3 days of incubation at $30^{\circ} \mathrm{C}$, the number of colony forming units (CFUs) was counted and the mean of each dilution was determined. The MSM was composed of (in mg L ${ }^{-1}$ ): $\left(\mathrm{NH}_{4}\right)_{2} \mathrm{SO}_{4}, 1,000$; $\mathrm{K}_{2} \mathrm{HPO}_{4}, 800 ; \mathrm{KH}_{2} \mathrm{PO}_{4}, 200 ; \mathrm{MgSO}_{4} \cdot 7 \mathrm{H}_{2} \mathrm{O}, 200$; $\mathrm{CaCl}_{2} \cdot 2 \mathrm{H}_{2} \mathrm{O}, 100$; and trace elements made up of $\mathrm{FeSO}_{4} \cdot 7 \mathrm{H}_{2} \mathrm{O}, 12 ; \mathrm{MnSO}_{4} \cdot 7 \mathrm{H}_{2} \mathrm{O}, 3 ; \mathrm{ZnSO}_{4} \cdot 7 \mathrm{H}_{2} \mathrm{O}, 3$; $\mathrm{CoSO}_{4} \cdot 7 \mathrm{H}_{2} \mathrm{O}, 1 ;\left(\mathrm{NH}_{4}\right)_{6} \mathrm{Mo}_{7} \mathrm{O}_{24} \cdot 4 \mathrm{H}_{2} \mathrm{O}, 1$; and $15 \mathrm{~g}$ agar. The $\mathrm{pH}$ was adjusted to 7.0-7.2. The MSM was prepared in artificial seawater at $10 \mathrm{ppt}$ (parts per thousands). In order to assess the total microflora, we used rich medium (M 863): glucose, $20 \mathrm{~g} / \mathrm{L}$; peptone, $10 \mathrm{~g} / \mathrm{L}$; yeast extract, $10 \mathrm{~g} / \mathrm{L}$; and Tween $80,1 \mathrm{~mL} / \mathrm{L}$. For cultures on solid medium, this medium was supplemented with $15 \mathrm{~g} / \mathrm{L}$ of agar.

\subsection{Statistical Analysis}

The mean values were compared using an analysis of variance (ANOVA) test, with a $p$ value $\leq 0.05$. The differences in the various rates of diesel reduction were also analyzed using the same test. An ANOVA was used to calculate the differences between the initial and final total petroleum hydrocarbon (TPH) concentrations in the treated flasks and the control flasks. All statistical analyses were performed using MINITAB $15^{\circledR}$ statistical software (French version).

\section{Results}

The current study aims to assess the potential degradation ability of Rhodococcus erythropolis T902.1, an exogenous bacterial strain, in the presence of a mixture of four PAHs, to assess the ability of $R$. erythropolis in pure culture and in association with the endogenous microflora and to evaluate and compare different PAH degradation strategies. The results are presented in two parts. The first part focuses on the experiment conducted in sterile conditions and the second part on the experiment conducted in nonsterile conditions.

\subsection{Experiments with Sterilized Mangrove Sediments and Exogenous Rhodococcus}

\subsubsection{Evolution of pH over 5 Weeks of Biodegradation}

The different $\mathrm{pH}$ curves showed that the $\mathrm{pH}$ remained almost constant (between 7 and 7.5) in the control flasks. In the flasks containing sterile sediments, the $\mathrm{pH}$ fell to between 5.5 and 6 after 5 weeks, irrespective of the treatment (Fig. 1). This decrease was probably due to the release of ions and protons formed during PAH degradation.

\subsubsection{Evolution of Microflora in the Flasks}

During the experiment, we evaluated the evolution of the total microflora and active microflora in the flasks for each treatment in the sterile sediments. The growth of $R$. erythropolis was better in flasks where the nutrient solution had been added in the first week. The biomass in these flasks, however, decreased with time and was lower than the one in the flasks to which no nutrient solution had been added. The steady drop in $\mathrm{pH}$ over the 5 weeks of treatment might explain the slower bacterial growth in various flasks. The 5.5-6 pH range reached during the last 2 weeks of treatment was not optimal for bacterial growth (Fig. 2). The decrease in microbial growth and the degradation of PAHs in the flasks could be attributed to the decrease in $\mathrm{pH}$.

Statistical analyses showed significant differences in the number of microorganisms, depending on the treatments. In flasks with sterile sediments, there was a 
Fig. 1 Evolution of $\mathrm{pH}$ in mangrove sterile sediments after 5 weeks under two strategies

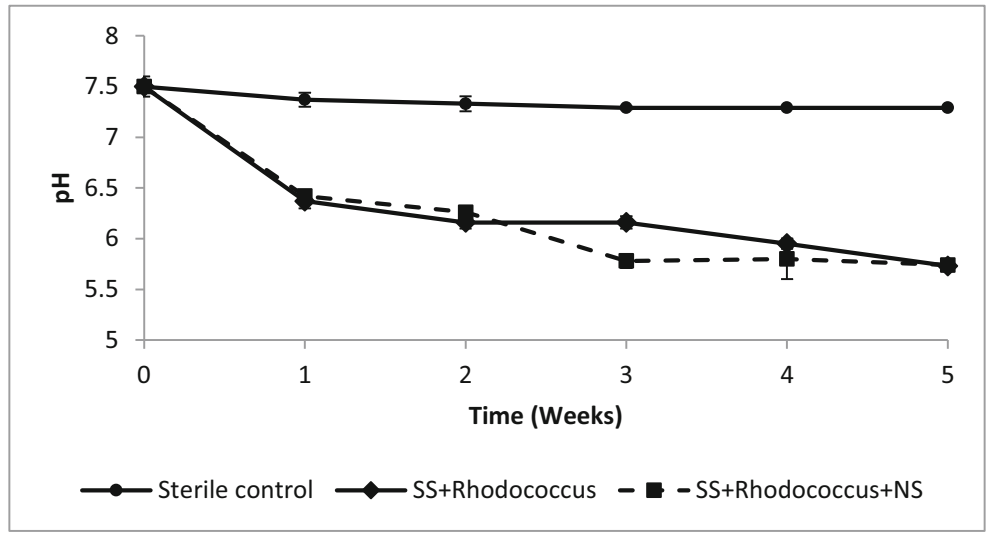

significant difference between treatments with or without the addition of nutrients. In the treatments involving an addition of nutrients, the concentration in total microorganisms after 5 weeks of treatment moved from $10^{7} \mathrm{CFU} /$ $\mathrm{g}$ of dry matter to $6 \times 10^{6} \mathrm{CFU} / \mathrm{g}$ of dry matter. On the other hand, the concentration in degrading bacteria moved from $10^{7} \mathrm{CFU} / \mathrm{g}$ of dry matter to $2 \times 10^{6} \mathrm{CFU} / \mathrm{g}$ of dry matter. In treatments without the addition of nutrients, the bacterial concentrations were $1 \times 10^{6} \mathrm{CFU} / \mathrm{g}$ of dry matter and $2 \times 10^{5} \mathrm{CFU} / \mathrm{g}$ of dry matter for total microflora and degrading microflora, respectively. This difference in the concentration in microorganisms could be the effect of nitrogen $(\mathrm{N})$ and phosphorus $(\mathrm{P})$ in the nutrient solution. Both nutrients play a key role in the survival and metabolism of the microorganisms and promote their adaptation to the pollutant.
Fig. 2 Evolution of microorganisms in mangrove sterile sediments after 5 weeks according to two strategies (presence or absence of nutrients)
Total aerobic heterotrophs

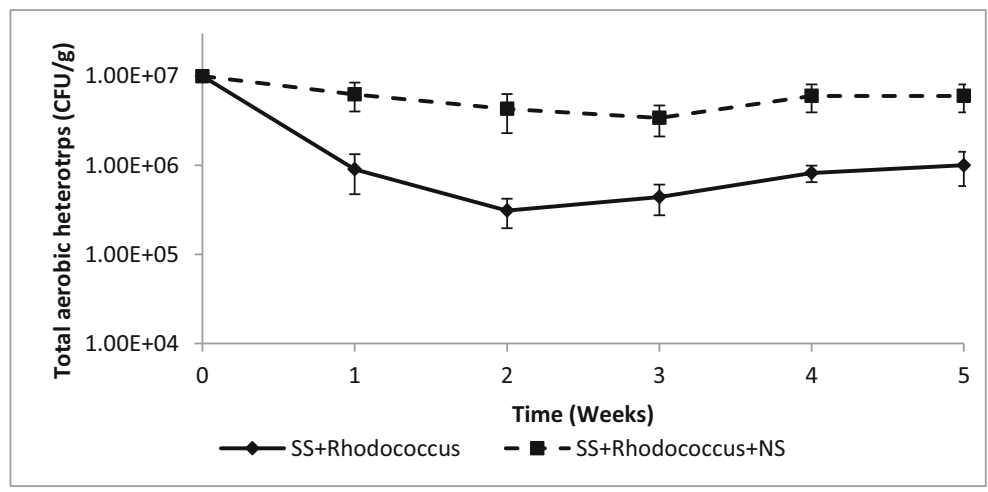

PAH degraders

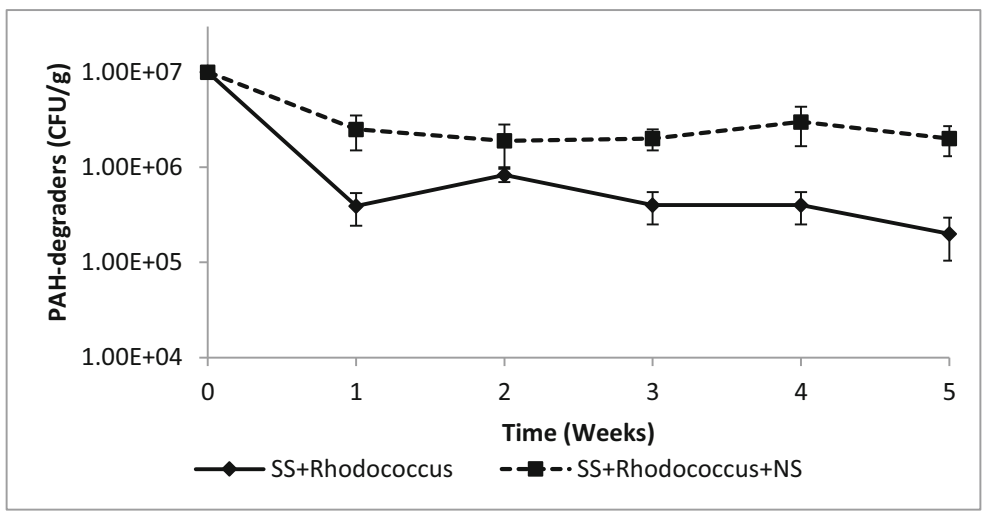


3.2 Degradation of Mixed PAHs Under Two Strategies in Sterile Sediments

After 5 weeks of experiment, the results for the control flasks, without bacteria or nutrients, showed a PAH decrease of $1.3,2.8,0.8$, and $0.4 \%$ for phenanthrene, anthracene, fluoranthene, and pyrene, respectively. These levels of degradation were evaporative losses without any microbiological implications. In the presence of bacteria (Fig. 3), the results show, after 5 weeks of treatment, $100 \%$ of degradation of phenanthrene, anthracene, and fluoranthene in both flasks containing $R$. erythropolis and $R$. erythropolis with nutrients. Over the same period, pyrene degradation was incomplete. There was a degradation rate of $75.4 \pm 10.5 \%$ in the flasks with only $R$. erythropolis and $82.2 \pm 1.7 \%$ in the flasks with bacteria and the nutrient solution. The statistical results obtained with a controlled factor ANOVA ( simultaneous confidence intervals Tukey $=95 \%$ ) showed that there had been a significant difference between the first 3 weeks in the degradation of all PAHs, irrespective of treatment. Anthracene, phenanthrene, and fluoranthene were more degraded than pyrene. This molecule requires more time to be degraded completely (Fig. 3).

\subsection{Experiments with Mangrove Sediments With or Without Exogenous Rhodococcus}

\subsubsection{Evolution of pH over 5 Weeks of Biodegradation}

The $\mathrm{pH}$ decreased irrespective of the treatment. It was more acidic after 5 weeks of treatment, decreasing between 5 and 6 (Fig. 4). This pH drop was certainly due to acid metabolites derived from the degradation of various PAHs in the environment. The $\mathrm{pH}$ could also decrease due to biodegradation of other molecules such as organic matter that are involved in the sediments from this kind of complex environment.

\subsubsection{Evolution of Microflora in the Flasks}

During the experiment, we evaluated the evolution of the total microflora and active microflora in the flasks for each treatment in nonsterile sediments. The evolution of the total microflora was comparable with that of the active microflora; for all the treatments, there was a decrease in concentrations over the 5-week period. In the flasks corresponding to the bioaugmentation treatment and the combined bioaugmentation/ biostimulation treatment, the microflora was higher than in the natural attenuation and biostimulation experiments. In the third week, the biomass in the sediment in the biostimulation treatment was comparable with that in biostimulation/bioaugmentation treatment. This biomass was higher than that in the bioaugmentation and natural attenuation treatments. The statistical analysis showed no significant difference as for the concentrations in microorganisms according to the treatments. This was observed for both total and degrading microflora. With regard to the total microflora, there was a significant difference between the natural attenuation treatment and all the other treatments. The statistical analysis also showed a significant difference between the bioaugmentation/biostimulation treatment and the biostimulation and bioaugmentation treatments. The difference in the total microflora concentration between the biostimulation and bioaugmentation treatments was not significant. The observation of the fact that the total microflora concentration depended on the treatment in nonsterile sediments was also true for degrading microflora. Nutrients played an important role in the growth of microorganisms (Fig. 5).

\subsubsection{Degradation of Mixed PAHs Under Different Strategies in Nonsterile Sediments}

After 5 weeks of experimentation, the results showed bacterial activity in the metabolism of different PAHs present in the medium. This activity depended on the treatment and the type of pollutant considered (Fig. 6). For anthracene, the results from the combined biostimulation/bioaugmentation treatment differed significantly from those obtained for the other treatments over the first 4 weeks. The biostimulation and bioaugmentation treatments were comparable.

For phenanthrene, after 5 weeks of experimentation, the results showed a degradation rate of $67.8 \pm 11.7 \%$ with the natural attenuation treatment, $81.1 \pm 7.5 \%$ with the biostimulation treatment, and $100 \%$ with the bioaugmentation and biostimulation/bioaugmentation treatments. The statistical analysis showed a significant difference between the natural attenuation treatment and the biostimulation/bioaugmentation treatment in the first week. There was also a significant difference between the biostimulation and the bioaugmentation/ biostimulation treatments from the second week. There was no significant difference, however, between the 


\section{Anthracene}

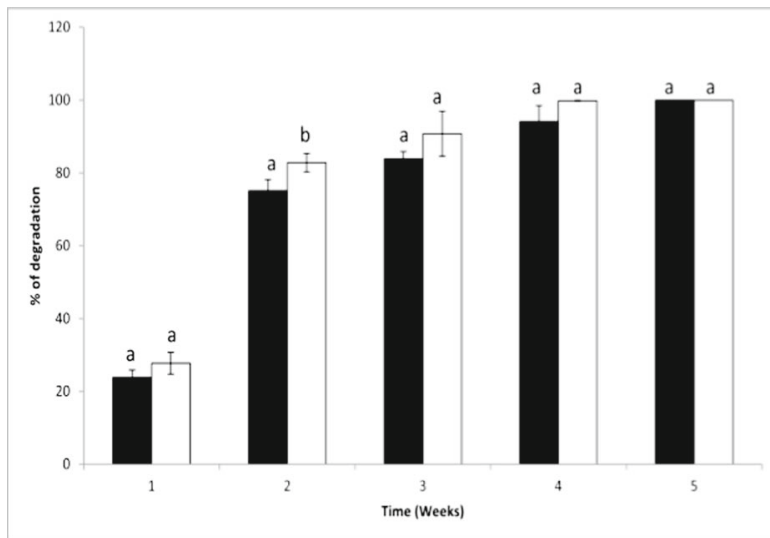

Pyrene

\section{Phenanthrene}

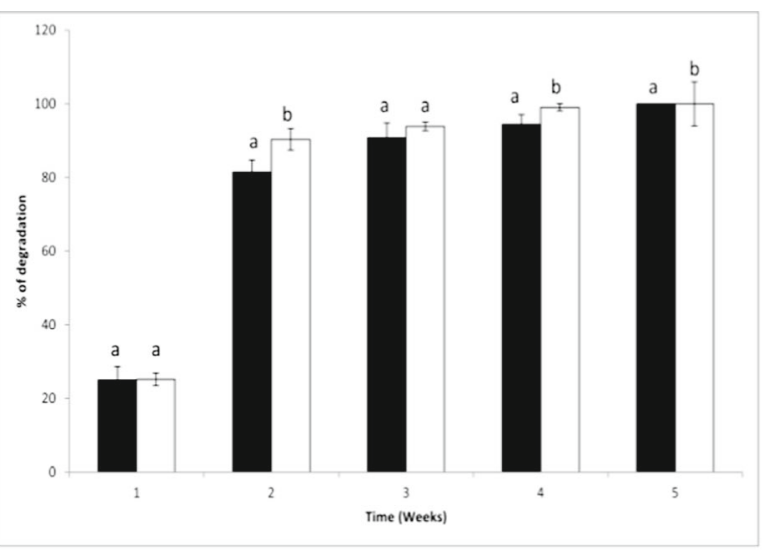

\section{Fluoranthrene}

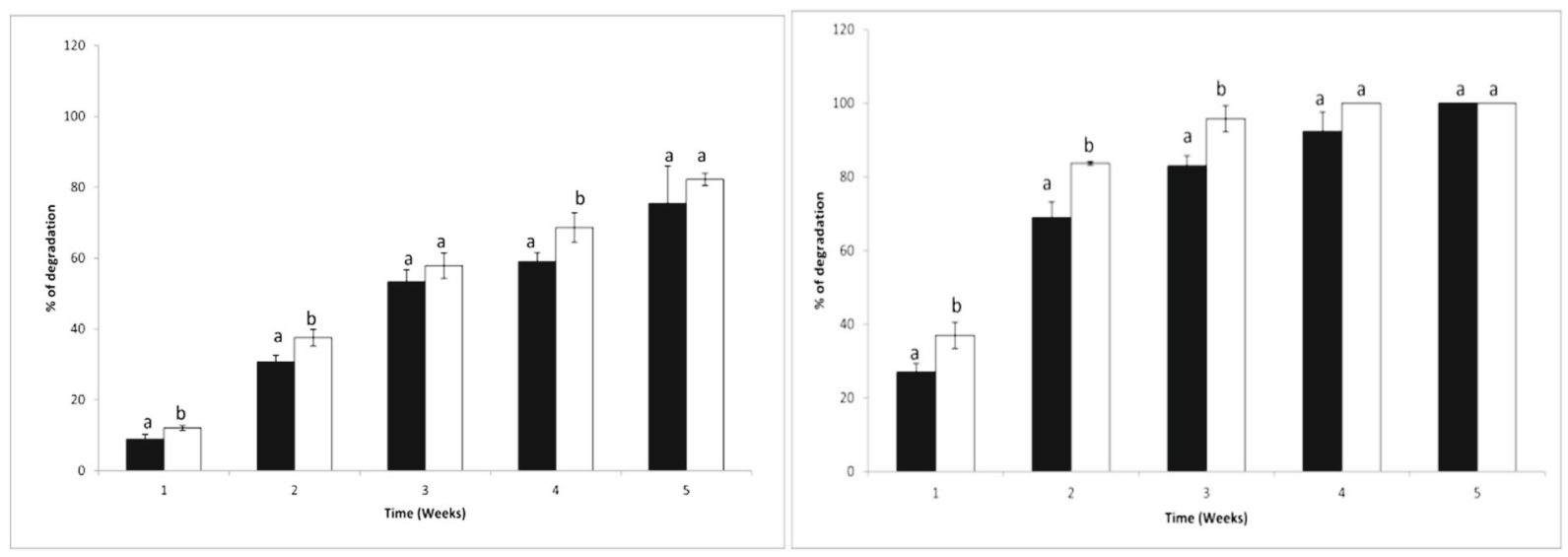

\section{R. erythropolis \\ R. erythropolis + Nutrient solution}

Fig. 3 Biodegradation percentage of anthracene (Ant), phenanthrene (Phe), pyrene (Pyr), and fluoranthene (Flt) in mangrove sterile sediments during 5 weeks

Fig. 4 Evolution of $\mathrm{pH}$ in mangrove nonsterile sediments under different strategies

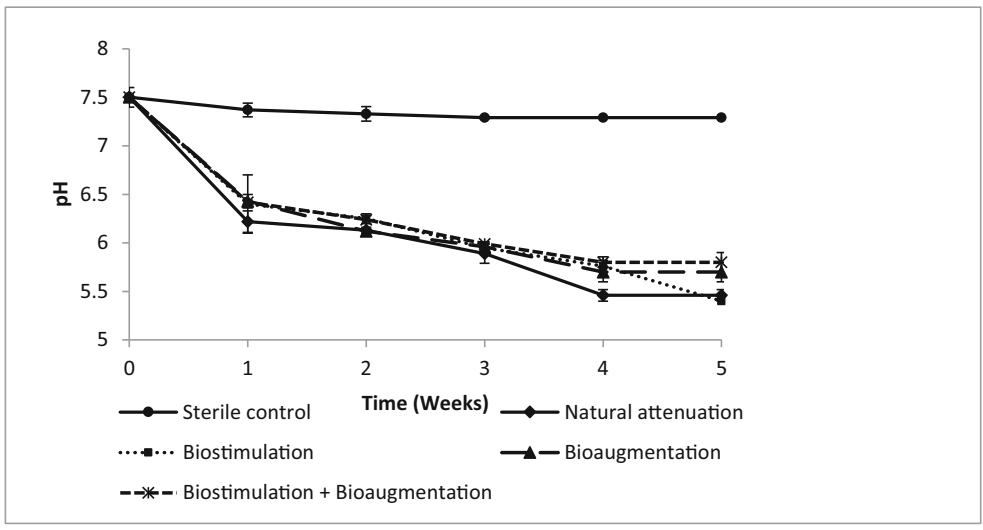


Fig. 5 Evolution of microorganisms in mangrove nonsterile sediments over 5 weeks under different strategies
Total aerobic heterotrophs

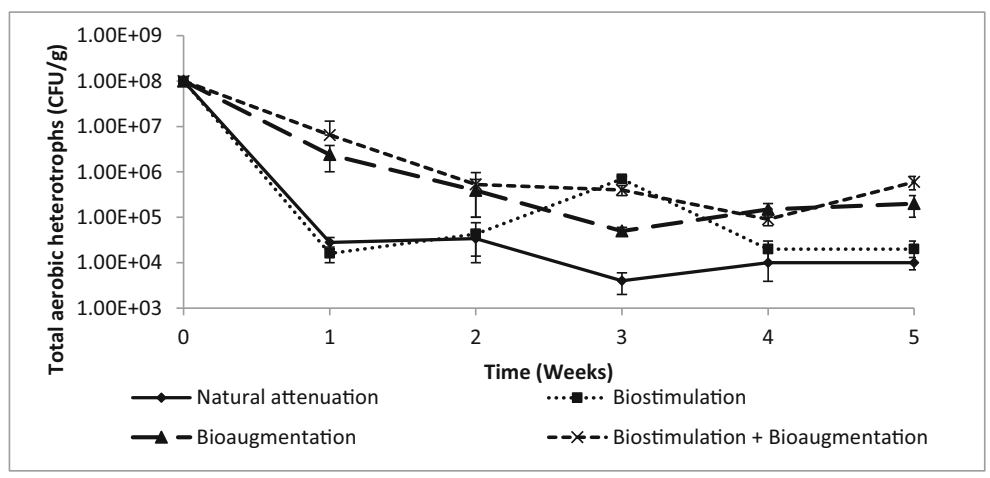

PAHs degraders

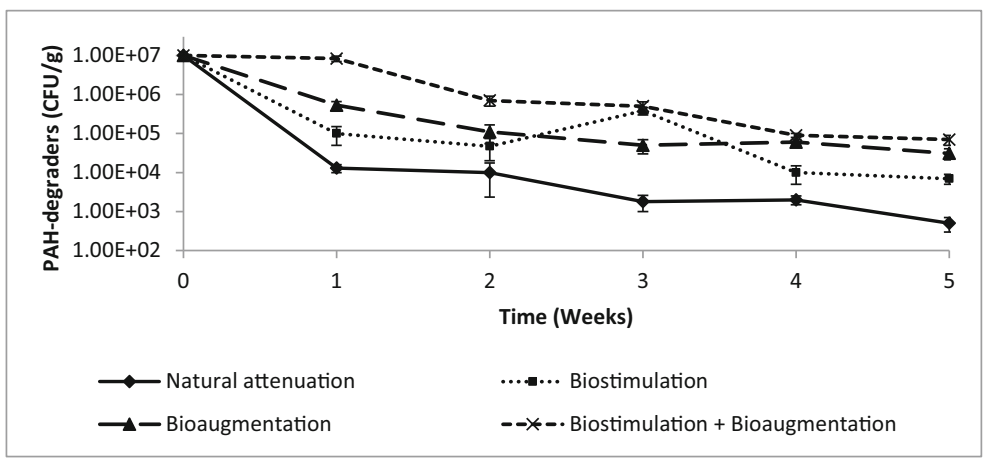

biostimulation and bioaugmentation treatments during the first 3 weeks, but the difference was significant in the last 2 weeks. The statistical analysis showed a significant difference between the first and second weeks, irrespective of the treatment. The degradation rate was significantly different between the fifth week and the first 3 weeks. For pyrene, after 5 weeks of treatment, the natural attenuation degradation rate was $35.2 \pm 2.4 \%$, but $59.5 \pm 2.4 \%$ for the biostimulation treatment, 66.3 $\pm 1.2 \%$ for the bioaugmentation treatment, and $91.1 \pm$ $6.7 \%$ for the biostimulation/bioaugmentation treatment. The degradation rates for the biostimulation/ bioaugmentation treatment differed significantly from other treatments over the 5-week period of the experiment. The results obtained for the biostimulation and bioaugmentation treatments were comparable; they differed significantly from the natural attenuation treatment in the last 3 weeks. For fluoranthene, the degradation rates for the biostimulation/bioaugmentation treatment differed significantly from those obtained for the natural attenuation and biostimulation treatments. In general, irrespective of the treatment, the degradation rates of the four PAHs in the fifth week differed significantly from those obtained in the first 3 weeks. Similarly, the results for the fourth week differed significantly from those of the first 2 weeks (see Table 1).

\section{Discussion}

PAHs are organic compounds with two or more benzene rings. They are degraded biologically by various microorganisms, such as bacteria and fungi, usually under aerobic conditions. Most microorganisms reported to mineralize PAHs under aerobic conditions use similar metabolic pathways. The microbial degradation of PAHs in aquatic and terrestrial ecosystems is strongly influenced by a variety of abiotic and biotic factors, including temperature, $\mathrm{pH}$, soil type, aeration, nutrients, depth, diffusion, microbial adaptations, bioavailability, previous chemical exposure, water availability, sediment toxicity, PAH physicochemical properties, PAH concentration, and seasonal factors (Cerniglia 1992).

In order to degrade anthracene, phenanthrene, pyrene, and fluoranthene, this experiment adapted certain parameters - type and nature of pollutants - adding 
Anthracene

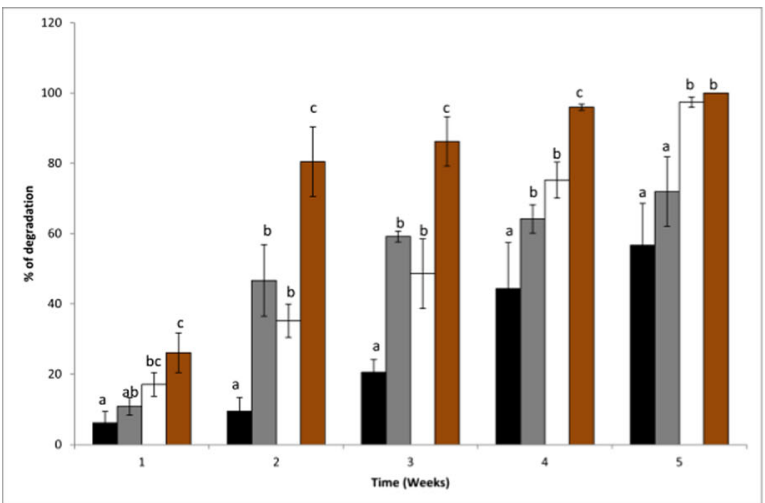

Pyrene

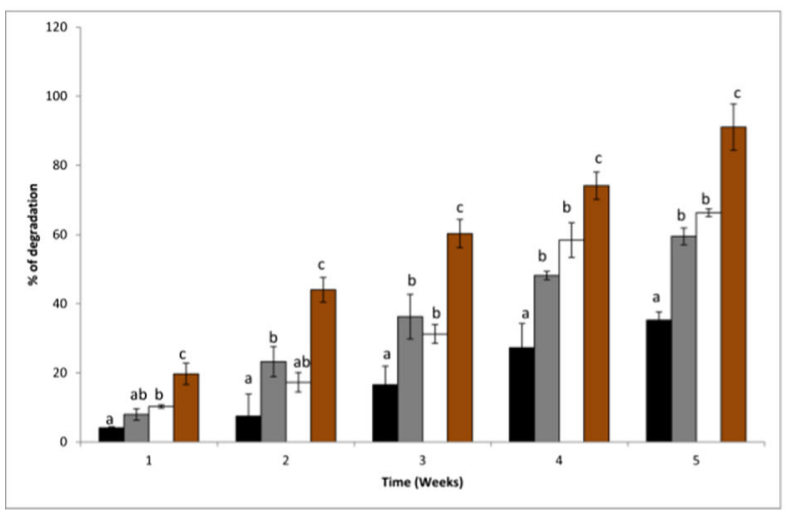

\Natural attenuation
Phenanthrene

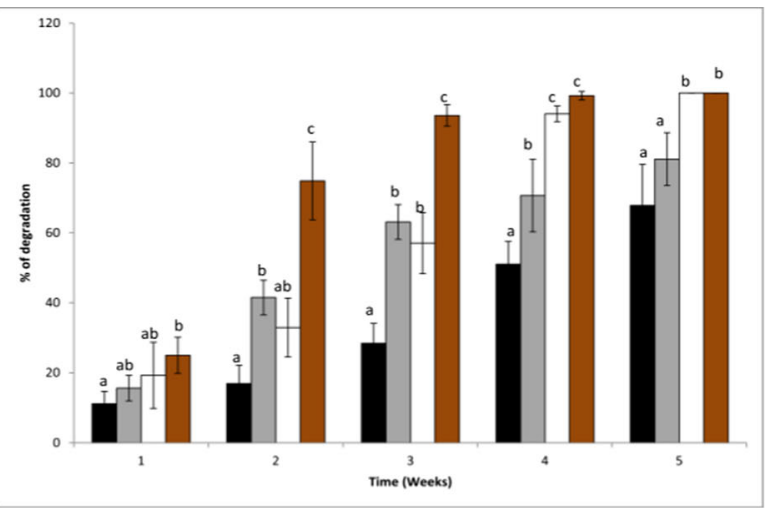

Fluoranthene

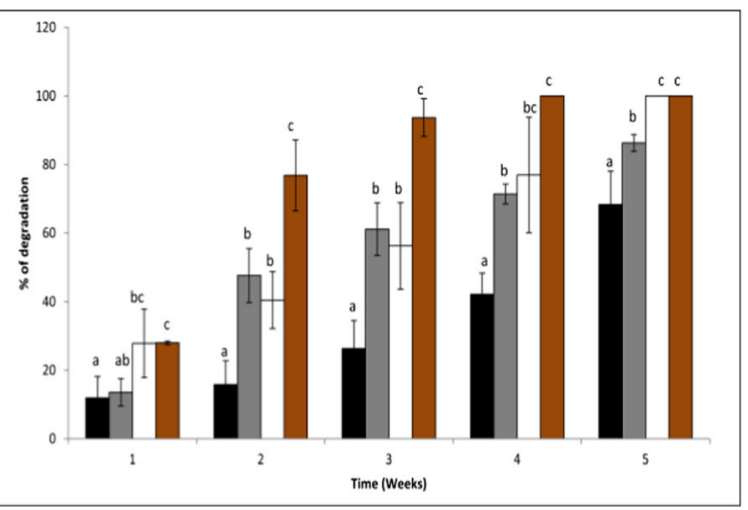

Bioaugmentation

\section{Biostimulation and bioaugmentation}

Fig. 6 Biodegradation rate of anthracene (Ant), phenanthrene (Phe), pyrene (Pyr), and fluoranthene (Flt) in mangrove nonsterile sediments during 5 weeks degradation according to different strategies

$R$. erythropolis as an exogenous pure strain for the bioaugmentation treatment, maintaining the temperature at $30^{\circ} \mathrm{C}$, monitoring the $\mathrm{pH}$ evolution and the evolution of total microflora and degrading microflora, and the contribution of nutrients to the bio-stimulation strategy. Several studies have shown that mangrove sediments contain a specific microflora capable of degrading hydrocarbons. Brito et al. (2006) isolated and identified a number of PAH-degrading bacteria in the mangroves. The experiment showed that Marinobacter and Pseudomonas species were able to degrade fluoranthene and pyrene, Alcanivorax species degraded octane, Microbulbifer species degraded fluoranthene and naphthalene, and Sphingomonas species degraded pristane. Tam et al. (2002) conducted a phenanthrene degradation experiment using a bacterial consortium isolated in mangrove sediments polluted with hydrocarbons. This consortium was used as an inoculum in flasks containing mangrove sediments added with phenanthrene (concentration $200 \mathrm{mg} \mathrm{l}^{-1}$ ) as the sole carbon source. Six days after this treatment, $78 \%$ of the phenanthrene was degraded. Later, Tam et al. (2008) conducted a greenhouse experiment in microcosm using samples of mangrove sediments. The level of pollution of the samples was $170 \mathrm{ng} \mathrm{g}^{-1}$ of dry matter (total of 16 priority PAHs according to the US Environmental Protection Agency). After 154 days of culture, $90 \%$ fluorene, $80 \%$ phenanthrene, $70 \%$ fluoranthene, $68 \%$ pyrene, and $32 \%$ benzo(a)pyrene were degraded by natural attenuation. Several experiments with different bacterial strains were conducted on mangrove soils contaminated by hydrocarbons, and the 


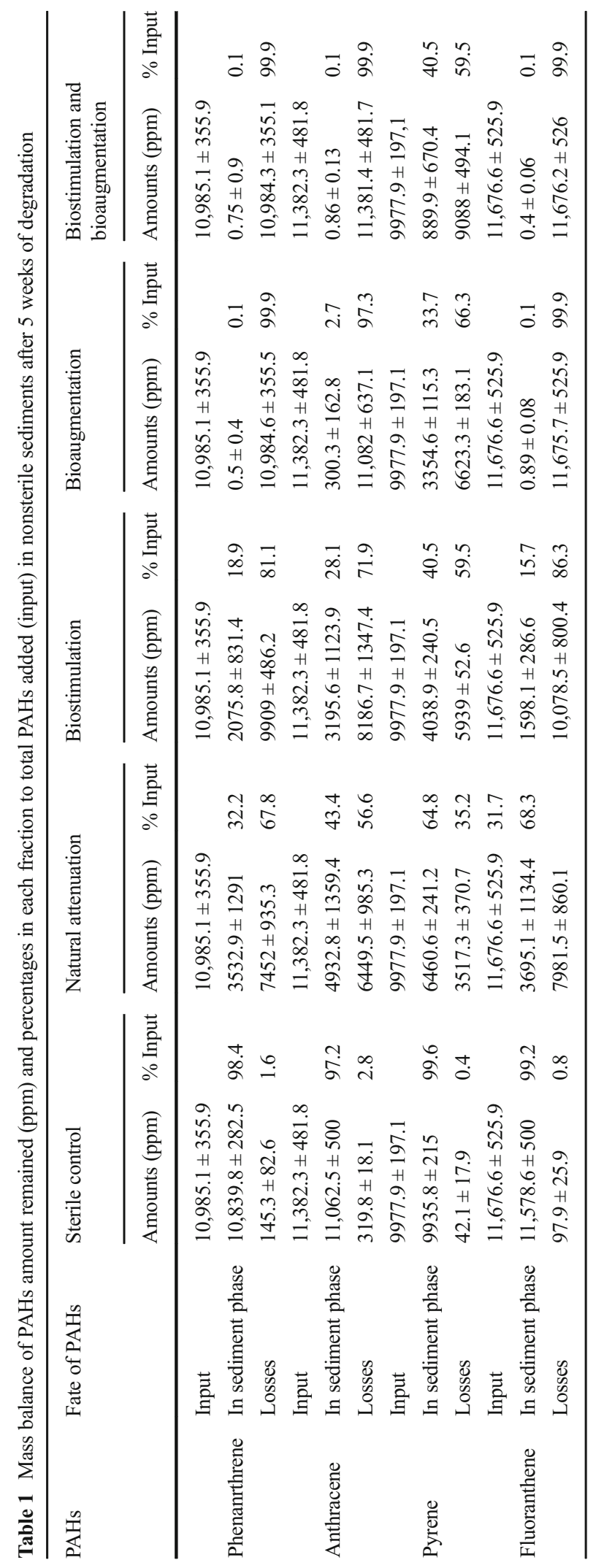


results obtained during the various treatments illustrated the adaptation of microorganisms to different doses of pollutant (Haritash et al. 2009). For the degradation of three PAHs (fluorene, phenanthrene, and pyrene) found in mangrove sediments, Yu et al. (2005) used an enriched bacterial consortium containing three bacterial species (Rhodococcus sp., Acinetobacter sp., and Pseudomonas sp.). The starting PAH concentrations (total of 16 priority PAHs from the US EPA) in sediments varied from 1.162 to $3.322 \mathrm{ng} \mathrm{g}^{-1}$ of dry matter. Four weeks after treatment, more than $99 \%$ of the fluorene and phenanthrene and only $30 \%$ of the pyrene had been degraded by natural attenuation. Over $97 \%$ of the three PAHs were degraded by biostimulation activated by a nutrient solution. The bioaugmentation treatment percentages were similar to those of natural attenuation. These results show that, without taking the time factor into account, some endogenous and exogenous microorganisms (pure strains or consortium) are able to degrade hydrocarbons in mangrove sediments. In our study, the temperature was set at $30^{\circ} \mathrm{C}$. Temperature can directly or indirectly affect biodegradation. This is an important factor in the growth and activity of microorganisms. It causes an increase in the level of metabolic reactions. According to a study by Song et al. (1990), by applying different temperatures $\left(17,27\right.$, and $\left.37^{\circ} \mathrm{C}\right)$, the rate of hydrocarbon reduction was the best at $27^{\circ} \mathrm{C}$ for all the pollutants tested. Although it is well established that temperature is an important factor in the growth and activity of microorganisms in the hydrocarbon biodegradation process, some studies have shown an almost complete inhibition of biodegradation at $5{ }^{\circ} \mathrm{C}$ (Baker 1994). Our experiment was conducted in optimal temperature conditions to improve growth and the bacterial metabolism $\left(30^{\circ} \mathrm{C}\right)$. Mangroves are ecosystems that are usually found in tropical zones. Temperature in these ecosystems $\left(25-30^{\circ} \mathrm{C}\right)$ should not be a limiting factor in the degradation of hydrocarbons in sediments. Monitoring the $\mathrm{pH}$ evolution enabled us to point out the good conditions to achieve an effective biodegradation. At the beginning of the experiment, the $\mathrm{pH}$ value was 7.5 and, after 5 weeks, it was 5.46. Baker (1994) noted that biodegradation is usually faster when it occurs under neutral $\mathrm{pH}$ conditions. Some studies have shown that the digestion of some pollutants is slower in groundwater and certain lakes where the $\mathrm{pH}$ is more acidic ( $\mathrm{pH} 4.87$ ). The drop in $\mathrm{pH}$ was probably due to acidic metabolites (such as phenanthrene dihydrodiol, dihydroxy phenanthrene, phthalic acid, dihydroxy pyrene, lactone, etc.), derived from PAH degradation. In polluted mangrove ecosystems, the rapid degradation of hydrocarbons depends on environmental conditions. In addition to temperature, optimum $\mathrm{pH}$, and the presence of PAH degraders, nutrients are also required. Nutrients accelerate bacterial growth, which directly affects hydrocarbon degradation. Moreira et al. (2011) conducted an experiment that used two biodegradation models (assisted phytoremediation with Rhizophora mangle and only bioremediation) to identify the most efficient process for hydrocarbon degradation in mangrove sediments. After 90 days, the results showed a pollutant abatement rate of $87 \%$ for assisted phytoremediation and $70 \%$ for bioremediation. The enumeration of the total microflora showed an increase in the number of bacteria from $2 \times 10^{5}$ to $2 \times$ $10^{7} \mathrm{CFU} \mathrm{g}^{-1}$ beyond 30 days where there was mangrove. For bioremediation, there was a slight increase in total microflora $\left(2 \times 10^{5}\right.$ to $\left.1.8 \times 10^{6} \mathrm{CFU} \mathrm{g}^{-1}\right)$ showing that, in the presence of plants, root exudates are secreted into the rhizosphere microflora, providing favorable conditions for growth (Espinosa et al. 2005) and stimulating pollutant degradation (Joner et al. 2005). The hydrocarbon contamination, especially PAHs, may firstly result in a significant reduction in the amount of nutrients available to plants in soil. In fact, hydrocarbons are a major source of carbon but do not contain nitrogen or phosphorus. When microorganisms degrade PAHs, they consume the nutrients available in the environment, causing deficiencies and increasing the existing competition phenomena. Nutrient addition (generally nitrogen and phosphorus) can enhance biodegradation of oil under nutrient-limited conditions. Similarly, the addition of nutrients (nitrogen and phosphorus) in polluted soils can stimulate the bacterial growth and therefore increase the rate of hydrocarbon degradation. Nutrients and root exudates stimulate bacterial growth in mangrove ecosystems. Lu et al. (2011) conducted a greenhouse experiment to assess the rate of degradation of phenanthrene $\left(10 \mathrm{mg} \mathrm{kg}^{-1}\right)$ and pyrene $\left(10 \mathrm{mg} \mathrm{kg}^{-1}\right)$ in the rhizosphere of Kandelia candel. The system was implemented using laminar rhizoboxes divided into eight compartments, separated at different distances from the root surface. After 60 days of plant growth, they observed abatement rates of 47.7 and $37.6 \%$ for phenanthrene and pyrene, respectively. The intense microbial activity in the rhizosphere significantly improved the rate of degradation of the contaminants. In our experiment, we used $\mathrm{N}$ and $\mathrm{P}$ as nutrients. Kinney 
et al. (1969) asserted that $\mathrm{N}$ and $\mathrm{P}$ accelerate the biodegradation process of hydrocarbons in seawater. Despite the availability of $\mathrm{C}$ from the hydrocarbons for microbial growth, microorganisms need $\mathrm{N}$ and $\mathrm{P}$ to metabolize carbon compounds. The availability of these two nutrients is a key parameter of biodegradation. $\mathrm{N}$ and $\mathrm{P}$ must be available to ensure appropriate $\mathrm{C} / \mathrm{N}$ and $\mathrm{C} / \mathrm{P}$ ratios, sufficient for optimal microbial growth and metabolism, which increases the rate of hydrocarbon degradation.

Two different $\mathrm{C} / \mathrm{N} / \mathrm{P}$ ratios are recommended for $\mathrm{PAH}$ degradation. The first $\mathrm{C} / \mathrm{N} / \mathrm{P}$ molar mass ratio is $100 / 1.3 / 0.05$. The other one is based on average values of the elementary microbial composition (100/10/1) (Chen et al. 2008). Our study showed that nutrients are essential in the biostimulation treatment. The aim was to stimulate the growth and metabolism of endogenous microorganisms capable of degrading various PAHs. N and $\mathrm{P}$ are found in MSM.

Our results clearly showed that in sterile flasks, the nutrient input is not important. Rhodococcus erythropolis degrades anthracene, phenanthrene, and fluoranthene rapidly and completely. In contrast, the pyrene degradation was incomplete after 5 weeks. There was no significant difference between the two types of treatment in sterile flasks after 5 weeks. Rhodococcus sp. is a bacterial strain known for its capability to degrade hydrocarbons (Eun-Hee et al. 2011). Eun-Hee et al. (2011) used a combination of Rhodococcus sp. EH831 and a surfactant for the bioremediation of diesel-contaminated soils and compared this treatment with bioaugmentation using Rhodococcus species only. They reported that the addition of surfactant had no significant effect on the remediation performance. Many bacterial strains belonging to different genera isolated from soils contaminated with PAHs have different degradation abilities. The analytical results for nonsterile sediments have shown that nutrients play an important role in the biodegradation process. Other factors, such as the availability of inorganic nutrients, the presence of co-substrates, the redox potential environment, the substrate concentration, temperature, water activity, and the adaptive response of microorganisms, affect the biodegradation rates of PAHs in the soils (Zhang et al. 2006). Soil characteristics greatly influence the efficiency of microbial PAH degradation as well. The concentration of the available substrate is one of the most important parameters influencing PAH biodegradation (Cai et al. 2002).
Although the rate of biodegradation has been reported to be positively and directly related to substrate concentration, at higher concentrations, an adaptation period precedes active degradation (Jia et al. 2005; Johnsen et al. 2005). The availability of nutrients, such as $\mathrm{N}$ and $\mathrm{P}$, has also been reported to affect $\mathrm{PAH}$ persistence. Microbial activity usually functions optimally at a $\mathrm{C} / \mathrm{N} /$ P ratio of 100/5/1 (Zhou and Hua 2004). Therefore, for a complete bioremediation of soil containing elevated levels of PAHs, additional inputs of inorganic nutrients have to be provided to the soil microorganisms. A too high $\mathrm{N}$-concentration, however, inhibits some microorganisms (Yan et al. 2004).

In nonsterile sediments, the microflora is more effective with the addition of nutrients. The results of the bioaugmentation and bioaugmentation/biostimulation treatments were comparable with those of sterile sediments. It is known that the PAH biodegradation is related to various factors, including the number of aromatic rings and the type of fused ring structure (Walker and Colwell 1975; Herbs and Schwall 1978; Wild et al. 1991). We found that anthracene and phenanthrene (containing three benzene rings) were rapidly degraded. In literature, several experiments have shown that many three-ring PAHs are quickly decomposed and can be used as the primary substrate by organisms that degrade PAHs (Herbs and Schwall 1978; Gardner et al. 1979; Sims and Overcash 1983; Uthe 1991). The degradation of pyrene and fluoranthene (PAHs with four aromatic rings) occurs primarily by co-metabolism (Neff 1979). The differences in degradation are mainly due to the solubility of these PAHs. Some bacterial strains are able to use only the most soluble PAHs in water (TrzesickaMlynarz and Ward 1995). For this reason, much research focuses on the production of biosurfactants by degrading bacteria in order to increase the availability of PAHs (Arino et al. 1996; Burd and Ward 1996; Deziel et al. 1996). The bacterial strains belonging to different genera isolated from soils contaminated with PAHs differ in their ability to degrade these compounds. The most common bacteria in bioremediation, however, belong to the Pseudomonas and Rhodococcus genera. (Ramsay et al. 2000) showed that mangrove sediments contain a highly active microflora capable of degrading PAHs. For artificially polluted environments, the microorganisms need some time to adapt and to acclimate to pollutants in order to degrade them. In our study, we worked with slightly polluted mangrove sediments. We felt that a large artificial pollution of these sediments 
would adversely affect the microbial growth, resulting in a low PAH degradation. This led us to use $R$. erythropolis as the primary bacterium for bioaugmentation. Several bacteria, such as Rhodococcus spp., Bacillus spp., and Pseudomonas spp., were isolated from various hydrocarbon-contaminated soils. These bacteria used anthracene, phenanthrene, pyrene, and fluoranthene as sole $\mathrm{C}$ and energy sources (Kelley et al. 1993; Samanta et al. 2002). Fan and Krishnamurthy (1995) and Tian et al. (2008) reported that the reason for the high degradation capacity of these microorganisms was that they possess key enzymes, such as PAH dioxygenase and catechol oxygenase. These microorganisms degrade PAHs via metabolism or co-metabolism. Co-metabolism is especially relevant for the degradation of PAH mixtures.

\section{Conclusion}

This study was carried out to assess the response capacity of active microflora under stress conditions with a mixture of four PAHs. This approach enabled us to measure the degradation capacity of $R$. erythropolis in association with an endogenous microflora. We evaluated the potential of degradation of a mixture of four PAHs (anthracene, phenanthrene, pyrene, and fluoranthene) under different bio-treatments: natural attenuation, biostimulation, bioaugmentation, and a combination of biostimulation and bioaugmentation, with a bacterial consortium and $R$. erythropolis in aerobic conditions. The degradation results obtained in sterile sediments showed that $R$. erythropolis was able to degrade anthracene, phenanthrene, and fluoranthene completely after 5 weeks of treatment. The addition of a nutrient solution improved the degradation. Over the same period, the degradation of pyrene (four benzene rings) was not completed. The natural attenuation treatment proved to be less effective than the biostimulation or biostimulation/bioaugmentation treatments. The addition of nutrients had a positive effect on the microflora. The addition of $R$. erythropolis accelerated the degradation. The Rhodococcus strain is recognised for its ability to metabolize hydrocarbons. Its association with the endogenous microflora does not seem to be a problem. The degradation rates obtained were clearly determined by this association. The study also showed that the endogenous microflora, which has a low rate of degradation, needs time to adapt to the pollutant.

\section{References}

Arino, S., Marchal, R., \& Vandecasteele, J. P. (1996). Involvement of a rhamnolipid-producing strain of Pseudomonas aeruginosa in the degradation of polycyclic aromatic hydrocarbons by a bacterial community. Journal of Applied Microbiology, 84, 769-776.

Baker, K. H. (1994). Bioremediation of surface and subsurface soils. In K. H. Baker \& D. S. Herson (Eds.), Bioremediation (pp. 203-259). New York, USA: McGraw-Hill Inc.

Balba, M. T., Al-Awadhi, N., \& Al-Daher, R. (1998). Bioremediation of oil-contaminated soil: microbiological methods for feasibility assessment and field evaluation. Journal Microbiology Methods, 32, 155-164.

Banerjee, D. K., Fedorak, P. M., Hashimoto, A., Masliyah, J. H., Pickard, M. A., \& Gray, M. R. (1995). Monitoring the biological treatment of anthracene-contaminated soil in a rotating-drum bioreactor. Applied Microbiology and Biotechnology, 43, 521-528.

Bell, K. S., Philp, J. C., Aw, D. W. J., \& Christofi, N. (1998). The genus Rhodococcus. Journal Applied Microbiology, 85, 195210 .

Brito, E. M. S., Guyoneaud, R., Goñi-Urriza, M., RanchouPeyruse, A., Verbaere, A., Crapez, M. A., Wasserman, J. C., \& Duran, R. (2006). Characterization of hydrocarbonoclastic bacterial communities from mangrove sediments in Guanabara Bay, Brazil. Research in Microbiology, 157(8), 752-762.

Burd, G., \& Ward, O. P. (1996). Involvement of a surface-active high molecular weight factor in degradation of polycyclic aromatic hydrocarbons by Pseudomonas marginalis. Canadian Journal of Microbiology, 42, 791-797.

Burns, K. A., Codi, S., Swannell, R. J. P., \& Duke, N. C. (1999). Assessing the petroleum hydrocarbon potential of endogenous tropical marine wetland microorganisms: flask experiments. Mangroves and Salt Marshes, 3, 67-83.

Cai, Q. Y., Mo, C. H., Wu, Q. T., Wang, B. G., \& Zhu, X. Z. (2002). Effect of municipal sludges and chemical fertiluers on the content of polycyclic aromatic hydrocarbons (PAHs) in paddy soil grown Ipomoea aquatica Fossk. Acta Pedologica Sinica (in Chinese), 39(6), 887-891.

Cerniglia, C. E. (1993). Biodegradation of polycyclic aromatic hydrocarbons. Current Opinion Biotechnology, 4, 331-338.

Cerniglia, C. E. (1992). Biodegradation of polycyclic aromatic hydrocarbons. Biodegradation, 3, 351-368.

Chen, J., Wong, M. H., Wong, Y. S., \& Tam, N. F. Y. (2008). Multi-factors on biodegradation kinetics of polycyclic aromatic hydrocarbons (PAHs) by Sphingomonas sp. a bacterial strain isolated from mangrove sediment. Marine Pollution Bulletin, 57, 695-702.

de Carvalho, C. C. C. R. (2010). Adaptation of Rhodococcus to organic solvents. In H. M. Alvarez (Ed.), Biology of Rhodococcus (pp. 109-131). Berlin Heidelberg: Springer.

de Carvalho, C. C. C. R. (2012). Adaptation of Rhodococcus erythropolis cells for growth and bioremediation under extreme conditions. Resources Microbiology, 163, 125-136.

de Carvalho, C. C. C. R., Marques, M. P. C., Hachicho, N., \& Heipieper, H. J. (2014). Rapid adaptation of Rhodococcus erythropolis cells to salt stress by synthesizing 
polyunsaturated fatty acids. Applied Microbiology Biotechnology, 98, 5599-5606.

Deziel, E., Paquette, G., \& Villemur, R. (1996). Biosurfactant production by a soil Pseudomonas strain growing on polycyclic aromatic hydrocarbons. Applied Environmental Microbiology, 62, 1908-1912.

Dowty, R. A., Shaffer, G. P., Hester, M. W., Childers, G. W., Campo, F. M., \& Greene, M. C. (2001). Phytoremediation of small-scale oil spills in fresh marsh environments: a mesocosm simulation. Marine Environmental Research, 52, 195-211.

Erickson, D. C., Loehr, R. C., \& Neuhauser, E. F. (1993). PAH loss during bioremediation of manufactured gas plant site soil. Water Research, 27, 911-919.

Espinosa, E., Martinez, M. E., Torres, E. F., \& Rojas, M. G. (2005). Improvement of the hydrocarbon phytoremediation rate by Cyperus laxus Lam. inoculated with a microbial consortium in a model system. Chemosphere, 59, 405-413.

Eun-Hee, L., Kang, L. K., \& Cho, K.-S. (2011). Bioremediation of diesel-contaminated soils by natural attenuation, biostimulation and bioaugmentation employing Rhodococcus $s p$. EH831. Korean Journal of Microbiology Biotechnology, 39(1), 86-92.

Fan, C. Y., \& Krishnamurthy, M. (1995). Enzymes for enhancing bioremediation of petroleum-contaminated soils: a brief review. Air Waste Management Association, 45, 453-460.

Forsyth, J. V., Tsao, Y. M., \& Bleam, R. D. (1995). Bioremediation: when is augmentation needed. In R. E. Hinchee, J. Fredrickson, \& B. C. Alleman (Eds.), Bioaugmentation for Site Remediation (pp. 1-14). Columbus: Battelle Press.

Gardner, W. S., Lee, R. F., Tenore, K. R., \& Smith, L. W. (1979). Degradation of selected polycyclic aromatic hydrocarbons in coastal sediments: importance of microbes and polychaete worms. Water, Air, and Soil Pollution, 11, 339-347.

Haritash, A. K., \& Kaushik, C. P. (2009). Biodegradation aspects of polycyclic hydrocarbons (PAHs): a review. Journal of Hazardous Materials, 169, 1-15.

Herbs, S. E., \& Schwall, L. R. (1978). Microbial transformation of polycyclic aromatic hydrocarbons in pristine and petroleumcontaminated sediments. Applied Environmental Microbiology, 35, 306-316.

Hughes, J. B., Beckles, D. M., Chandra, S. D., \& Ward, C. H. (1997). Utilization of bioremediation processes for the treatment of PAH-contaminated sediments. Journal of Industrial Microbiology and Biotechnology, 18, 152-160.

Iwamoto, T., \& Nasu, M. (2001). Review: current bioremediation practice and perspective. Journal of Bioscience and Bioengineering, 92, 1-8.

Jia, L. Q., Qu, Z. Q., \& Quyang, Z. Y. (2005). Ecological behavior of linear alkylbenzene sulfonate (LAS) in soil-plant systems. Pedosphere, 15(2), 216-224.

Johnsen, A. R., Wick, L. Y., \& Harms, H. (2005). Principles of microbial PAH-degradation in soil. Environmental Pollution, 133, 71-84.

Joner, E. J., Corgie, S., Amellal, N., \& Leyval, C. (2005). Nutritional constraints to PAH degradation in a rhizosphere model. Soil Biology Biochemistry, 34, 859-864.

Juhasz, A. L., \& Naidu, R. (2000). Bioremediation of high molecular weight polycyclic aromatic hydrocarbons: a review of the microbial degradation of benzo [a] pyrene. International Biodeterioration \& Biodegradation, 45, 57-88.

Kastner, M., \& Mahro, B. (1996). Microbial degradation of polycyclic aromatic hydrocarbons in soils affected by the organic matrix of compost. Applied Microbiology and Biotechnology, 44, 668-675.

Ke, L., Wang, W. Q., Wong, T. W. Y., Wong, Y. S., \& Tam, N. F. Y. (2003). Removal of pyrene from contaminated sediments by mangrove microcosms. Chemosphere, 51, 25-34.

Kelley, I., Freeman, J. P., Evans, F. E., \& Cerniglia, C. E. (1993). Identification of metabolites from the degradation of fluoranthene by Mycobacterium sp. Strain PYR-1. Applied Environmental Microbiology, 59, 800-806.

Kinney, P. J., Button, D. K., \& Schell, D. M. (1969). Kinetics of dissipation and biodegradation of crude oil in Alaska's Cook Inlet. In Proceedings of 1969 Joint Conference on Prevention and Control of Oil Spills (pp. 333-340). Washington, D.C: American Petroleum Institute.

Kuyukina, M. S., \& Ivshina, I. B. (2010). Rhodococcus biosurfactants: biosynthesis, properties, and potential applications. In H. M. Alvarez (Ed.), Biology of Rhodococcus (pp. 291-313). Berlin Heidelberg: Springer.

Kuyukina, M. S., Ivshina, I. B., Makarov, S. O., Litvinenko, L. V., Cunningham, C. J., \& Philp, J. C. (2005). Effect of biosurfactants on crude oil desorption and mobilization in a soil system. Environmental International, 31, 155-161.

Lang, S., \& Philp, J. C. (1998). Surface-active lipids in rhodococci. Antonie van Leeuwenhoek, 74, 59-70.

Larkin, M. J., Kulakov, L. A., \& Allen, C. C. R. (2010a). Rhodococcus. In K. N. Timmis (Ed.), Handbook of Hydrocarbon and Lipid Microbiology (pp. 1839-1852). Heidelberg: Springer-Verlag.

Larkin, M. J., Kulakov, L. A., \& Allen, C. C. R. (2010b). Rhodococcus: genetics and functional genomics. In K. N. Timmis (Ed.), Handbook of Hydrocarbon and Lipid Microbiology (pp. 1345-1353). Heidelberg: Springer-Verlag.

Larkin, M. J., Kulakov, L. A., \& Allen, C. C. R. (2005). Biodegradation and Rhodococcus - masters of catabolic versatility. Environmental. Biotechnology, 16, 282-290.

Lu, H., Zhang, Y., Liu, B., Liu, J., Ye, J., \& Yan, C. (2011). Rhizodegradation gradients of phenanthrene and pyrene in sediment of mangrove (Kandelia candel (L.) Druce). Journal of Hazardous Material, 196, 263-269.

Luan, T. G., Yu, K. S. H., Zhong, Y., Zhou, H. W., Lan, C. Y., \& Tam, N. F. Y. (2006). Study of metabolites from the degradation of polycyclic aromatic hydrocarbons (PAHs) by bacterial consortium enriched from mangrove sediments. Chemosphere, 65, 2289-2296.

Marini, M., \& Frapiccini, E. (2013). Persistence of polycyclic aromatic hydrocarbons in sediments in the deeper area of the Northern Adriatic Sea (Mediterranean Sea). Chemosphere, 90, 1839-1846.

Martinkova, L., Uhnakova, B., Patek, M., Nesvera, J., \& Kren, V. (2009). Biodegradation potential of the genus Rhodococcus. Environmental International, 35, 162-177.

Masy, T., Demaneche, S., Tromme, O., Thonart, P., Jacques, P., Hiligsmann, S., \& Vogel, T. M. (2016). Hydrocarbon biostimulation and bioaugmentation in organic carbon and clayrich soils. Soil Biology \& Biochemistry, 99, 66-74.

Mills, M. A., Bonner, J. S., McDonald, T. J., Page, C. A., \& Autenrieth, R. L. (2003). Intrinsic bioremediation of a 
petroleum-impacted wetland. Marine Pollution Bulletin, 46, 887-899.

Mueller, J. G., Lantz, S. E., Blattmann, B. O., \& Chapman, P. J. (1991). Bench-scale evaluation of alternative biological treatment process for the remediation of pentachlorophenol and creosote contaminated materials: solid phase bioremediation. Environmental Science and Technology, 25, 1045-1055.

Moreira, I. T. A., Oliveira, O. M. C., Triguis, J. A., Dos Santos, A. M. P., Queiroz, A. F. S., Martins, C. M. S., Silva, C. S., \& Jesus, R. S. (2011). Phytoremediation using Rhizophora mangle $\mathrm{L}$. in mangrove sediments contaminated by persistent total petroleum hydrocarbons (TPH's). Microchemistry Journal, 29, 376-382.

Neff, J. M. (1979). Polycyclic aromatic hydrocarbons in the aquatic environment: sources, fate and biological effects. Essex, England: Applied Science Publishers, Ltd.

Park, K. S., Sims, R. C., \& Dupont, R. (1990). Transformations of PAHs in soil systems. Journal Environmental Engineering, 116, 632-640.

Puri, R. K., Ye, Q. P., Kapila, S., Lower, W. R., \& Puri, V. (1997). Plant uptake and metabolism of polychlorinated biphenyls PCBs. In W. Wang, J. W. Gorsuch, \& J. S. Hughes (Eds.), Plants for Environmental Studies (pp. 482-513). New York: CRC Press LLC.

Ramsay, M. A., Swannell, R. P. J., Shipton, W. A., Duke, N. C., \& Hill, R. T. (2000). Effect of bioremediation community in oiled mangrove sediments. Marine Pollution Bulletin, 41, 413-419.

Riser-Roberts, E. (1998). Remediation of petroleum contaminated soils: biological, physical, and chemical processes (pp. 5313). Boca Raton: Lewis Publishers.

Samanta, S. K., Singh, O. V., \& Jain, R. K. (2002). Polycyclic aromatic hydrocarbons: environmental pollution and bioremediation. Trends Biotechnology, 20, 243-248.

Sims, R. C., \& Overcash, M. R. (1983). Fate of polynuclear aromatic compounds (PNAs) in soil-plant systems. Residue Review, 1, 2-68.

Song, H. G., Wang, X., \& Bartha, R. (1990). Bioremediation potential of terrestrial fuel spills. Applied Environmental Microbiology, 56, 652-656.

Tam, N. F. Y., Guo, C. L., Yau, W., \& Wong, Y. S. (2002). Preliminary study on biodegradation of phenanthrene by bacteria isolated from mangrove sediments in Hong Kong. Marine Pollution Bulletin, 45, 316-324.

Tam, N. F. Y., \& Wong, Y. S. (2008). Effectiveness of bacterial inoculum and mangrove plants on remediation of sediment contaminated with polycyclic aromatic hydrocarbons. Marine Pollution Bulletin, 57, 716-726.

Tian, Y., Liu, H. J., Zheng, T. L., Kwon, K. K., Kim, S. J., \& Yan, C. L. (2008). PAHs contamination and bacterial communities in mangrove surface sediments of the Jiulong River Estuary. China Marine Pollution Bulletin, 57, 707-715.

Trzesicka-Mlynarz, D., \& Ward, O. P. (1995). Degradation of polycyclic aromatic hydrocarbons (PAHs) by a mixed culture and its components pure cultures, obtained from PAHcontaminated soil. Canadian Journal of Microbiology, 41, 470-476.

Uthe, J. F. (1991). Polycyclic aromatic hydrocarbons in the environment. Canadian Chemistry News, 43(7), 25-27.

Vogel, T. M. (1996). Bioaugmentation as a soil bioremediation approach. Current. Opinion and Biotechnology, 7, 311-316.

Walker, J. D., \& Colwell, R. R. (1975). Degradation of hydrocarbons and mixed hydrocarbon substrate by microorganisms from Chesapeake Bay. Progress Water Technology, 7, 83-91.

Wannoussa, W., Masy, T., Lambert, S. D., Heinrichs, B., Tasseroul, L., Al-Ahmad, A., Weekers, F., Thonart, P., \& Hiligsmann, S. (2015). Effect of iron nanoparticles synthesized by a sol-gel process on Rhodococcus erythropolis T902.1 for biphenyl degradation. Journal of Water Resource and Protection, 7, 264-277.

Weekers, F., Jacques, P., Springael, D., Mergeay, M., Diels, L., \& Thonart, P. (1999). Improving the catabolic functions of desiccation-tolerant soil bacteria. In B. H. Davison \& M. Finkelstein (Eds.), Twentieth Symposium on Biotechnology for Fuels and Chemicals (pp. 251-266). Gatlinburg, Tennesee: Humana Press.

Whyte, L. G., Slagman, S. J., Pietrantonio, F., Bourbonni_ere, L., Koval, S. F., Lawrence, J. R., Inniss, W. E., \& Greer, C. W. (1999). Physiological adaptations involved in alkane assimilation at a low temperature by Rhodococcus sp. strain Q15. Applied Environmental Microbiology, 65, 2961-2968.

Wild, S. R., Berrow, M. L., \& Jones, K. C. (1991). The persistence of polynuclear aromatic hydrocarbons (PAHs) in sewage sludge-amended agricultural soils. Environmental Pollution, 72, 141-57.

Yan, J., Cheng, S. P., Zhang, X. X., Shi, L., \& Zhu, J. (2004). Effect of four metals on the degradation of purified terephthalic acid wastewater by Phanaerochaete chrysosporium and strain Fhhh. Bulletin of Environmental Contamination Toxicology, 72, 387-393.

Yu, K. S. H., Wong, A. H. Y., Yau, K. W. Y., Wong, Y. S., \& Tam, N. F. Y. (2005). Natural attenuation, biostimulation and bioaugmentation on biodegradation of polycyclic aromatic hydrocarbons (PAHs) in mangrove sediments. Marine Pollution Bulletin, 51, 1071-1077.

Zhang, X. X., Cheng, S. P., Zhu, C. J., \& Sun, S. L. (2006). Microbial PAH-degradation in soil: degradation pathways and contributing factors. Pedosphere, 16(5), 555-565.

Zhou, Q. X., \& Hua, T. (2004). Bioremediation: a review of applications and problems to be resolved. Progress Natural Science, 14(11), 937-944. 